\title{
Homeobox gene Dlx-2 is implicated in metabolic stress-induced necrosis
}

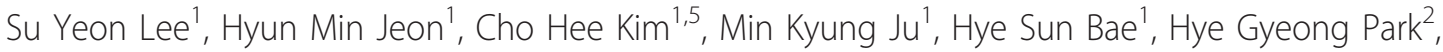 \\ Sung-Chul Lim ${ }^{3,4}$, Song ly $\operatorname{Han}^{3^{*}}$ and Ho Sung Kang ${ }^{1 *}$
}

\begin{abstract}
Background: In contrast to tumor-suppressive apoptosis and autophagic cell death, necrosis promotes tumor progression by releasing the pro-inflammatory and tumor-promoting cytokine high mobility group box 1 (HMGB1), and its presence in tumor patients is associated with poor prognosis. Thus, necrosis has important clinical implications in tumor development; however, its molecular mechanism remains poorly understood.

Results: In the present study, we show that Distal-less 2 (Dlx-2), a homeobox gene of the Dlx family that is involved in embryonic development, is induced in cancer cell lines dependently of reactive oxygen species (ROS) in response to glucose deprivation (GD), one of the metabolic stresses occurring in solid tumors. Increased Dlx-2 expression was also detected in the inner regions, which experience metabolic stress, of human tumors and of a multicellular tumor spheroid, an in vitro model of solid tumors. Dlx-2 short hairpin RNA (shRNA) inhibited metabolic stress-induced increase in propidium iodide-positive cell population and HMGB1 and lactate dehydrogenase (LDH) release, indicating the important role(s) of Dlx-2 in metabolic stress-induced necrosis. Dlx-2 shRNA appeared to exert its anti-necrotic effects by preventing metabolic stress-induced increases in mitochondrial ROS, which are responsible for triggering necrosis.
\end{abstract}

Conclusions: These results suggest that Dlx-2 may be involved in tumor progression via the regulation of metabolic stress-induced necrosis.

\section{Background}

Rapidly growing malignant tumors experience hypoxia and nutrient (e.g., glucose) deprivation, which occurs because of insufficient blood supply. Most tumor cells display higher rates of aerobic glycolysis; thus, glucose deprivation (GD) may be exacerbated in the inner regions of solid tumors. Under circumstances of hypoxia and nutrient deprivation, tumor cells either survive by overcoming the cytotoxic effects of such metabolic stresses via the activation of certain signal transduction pathways and gene regulatory mechanisms, or undergo cell death, especially in the innermost regions [1-4]. In tumors, metabolic stress-induced cell death mostly occurs by necrosis because most apoptotic and/or autophagic

\footnotetext{
* Correspondence: sihan@chosun.ac.kr; hspkang@pusan.ac.kr

'Department of Molecular Biology, College of Natural Sciences, Pusan

National University, Pusan 609-735, Korea

${ }^{3}$ Research Center for Resistant Cells, College of Medicine, Chosun University,

Gwangju 501-759, Korea

Full list of author information is available at the end of the article
}

programs are limited during the development of human tumors [5]. In fact, necrosis is commonly found in the core region of solid tumors. In apoptosis, cells are progressively fragmented into apoptotic bodies that are removed by professional phagocytic cells and in autophagic cell death, autophagosomes break down the damaged subcellular organelles. However, necrosis is characterized by the rupture of the cell membrane and release of cellular contents, including high mobility group box 1 (HMGB1) into the extracellular microenvironment, thereby causing a massive inflammatory response [6-10]. Necrotic cells recruit immune inflammatory cells, which exert a tumor-promoting activity by inducing angiogenesis, cancer cell proliferation, and invasiveness $[9,10]$. The HMGB1 protein is a highly conserved nuclear protein, which acts as a transcriptional regulator by controlling the activities of many transcription factors, including p53 and the Rel/NF- $\kappa$ B family [11-13]. Within the cytosol, HMGB1 also induces autophagy by interacting with and regulating Beclin 1 as a cofactor [14]. In addition,
C Biomed Central

(C) 2011 Lee et al; licensee BioMed Central Ltd. This is an Open Access article distributed under the terms of the Creative Commons Attribution License (http://creativecommons.org/licenses/by/2.0), which permits unrestricted use, distribution, and reproduction in any medium, provided the original work is properly cited. 
HMGB1 is released from necrotic cells and secreted by activated macrophages and functions as an extracellular signaling molecule [11-13]. HMGB1 binds to several receptors, including the receptor for advanced glycation end products (RAGEs) and Toll-like receptors (TLR)-2 and TLR-4, and promotes inflammation, cell proliferation, and tumor growth and metastasis. Thus, HMGB1 acts as a pro-inflammatory and tumor-promoting cytokine when released into the extracellular space during necrosis [11-13]. Recently, HMGB1 is known to be also released during autophagy and late apoptosis; for instance, anticancer agents that enhance autophagy and apoptosis cause HMGB1 release in cancer cells. In addition, the HMGB1 protein triggers autophagy or apoptosis in cancer cells, depending on its redox status. Reduced HMGB1 induces Beclin1-dependent autophagy and promotes tumor resistance to several chemotherapeutic agents, whereas oxidized HMGB1 induces apoptosis via the mitochondrial caspase-9/-3 pathway [15]. In cancer, overexpression of HMGB1 is associated with the hallmarks of cancer, including sustained proliferative potential and replicative immortality, angiogenesis, apoptosis resistance, self-sufficient growth, insensitivity to suppressors of growth, inflammation, and invasion and metastasis [16]. Thus, necrosis has the tumor-promoting potential as "a reparative cell death." Development of a necrotic core in cancer patients is correlated with increased tumor size, high-grade disease, and poor prognosis, such as emergence of chemoresistance and metastases [1-3]. Thus, metabolic stress-induced necrosis has important clinical implications. However, in contrast to programmed cell death, apoptosis, and autophagic cell death, the molecular mechanism underlying metabolic stress-induced necrosis in tumors is less investigated because it is generally considered as an accidental and genetically unprogrammed form of cell death.

The Distal-less (Dlx) homeobox gene family, a homolog of Drosophila distal-less (Dll), is crucial for embryonic development, morphogenesis, and tissue homeostasis, including neurogenesis and the formation of the distal regions of extending appendages in invertebrates and vertebrates $[17,18]$. Homeobox genes are characterized by a highly conserved 60 -amino acid homeodomain, which binds DNA elements containing a TAAT core motif. In humans, there are 6 Dlx genes, which exist as 3 bigene clusters: Dlx-1/Dlx-2, Dlx-5/Dlx-6, and Dlx-3/ Dlx-7 [19]. A growing number of homeobox genes have been shown to be deregulated in a variety of human tumors, and their deregulation is known to enhance cell survival and proliferation and prevent differentiation [20-23]. Deregulation of Dlx gene expression has also been reported in many human solid tumors and hematologic malignancies. For instance, Dlx-4 overexpression is observed in ovarian and breast cancers and strongly correlates with high tumor grade, advanced disease stage, and poor prognosis $[24,25]$. In addition, Dlx-5 is also unregulated in several human solid tumors, including lung, breast, and ovarian cancers, and T-cell lymphomas, and contributes to tumor progression [26-29]. Dlx-5 has been shown to promote tumor cell proliferation by directly binding the MYC promoter and upregulating MYC [30]. Dlx-7 is also known to regulate MYC expression in erythroleukemia cells [31].

In this study, we tried to identify the molecules that are involved in necrosis. Previously, we demonstrated that GD, one of the stresses that cause metabolic stress in tumors, could induce necrosis and HMGB1 release into the extracellular space in A549, HepG2, and MDA-MB231 cells [32]. We also showed that phorbol-12-myristate13-acetate (PMA), a protein kinase C (PKC) activator, prevented GD-induced necrosis in A549 cells, and switched the cell death mode to apoptosis by inhibiting reactive oxygen species (ROS) production by regulating manganese superoxide dismutase (MnSOD) and copperzinc SOD [32]. In this study, cDNA microarray analysis revealed that a homeobox gene Dlx-2 is induced in A549 cells that undergo necrosis but not in those that die by apoptosis. We also demonstrate that Dlx-2 is implicated in metabolic stress-induced necrosis, suggesting a possible role(s) of Dlx-2 in tumor progression.

\section{Results}

\section{DIx-2 is induced dependently of ROS during metabolic} stress-induced necrosis

The aim of this study was to identify the molecules that are involved in metabolic stress-induced necrosis. As demonstrated previously [32], PMA, a PKC activator, prevented GD-induced necrosis in A549 cells and switched the cell death mode to apoptosis (Figure 1A and 1B). To identify necrosis-linked molecules, we analyzed the gene expression profiling of A549 cells that were treated with GD or GD+PMA by cDNA microarrays. Of the 3,096 genes analyzed, approximately 200 were upregulated $>$ 2 -fold and approximately 150 were downregulated $>2$ fold (GEO accession no. GSE24271). One of the GD-inducible genes was Dlx-2, a homeobox gene of the Dlx family (Figure 1C); the Dlx-2 level was increased 9.04-fold during necrosis, whereas its level was not changed during apoptosis. Western blot analysis confirmed GD induction of Dlx2 in GD-treated A549 cells but not in A549 cells that were pretreated to PMA and then treated with GD, indicating that Dlx-2 expression increases only in the presence of necrosis (Figure 1D).

Dlx-2 has been shown to be expressed at higher levels in human breast cancers compared to other Dlx genes, including Dlx-1, Dlx-3, Dlx-4, and Dlx-6, although its precise roles in tumor biology are not clear [29]. Therefore, we investigated whether Dlx-2 is involved in metabolic 


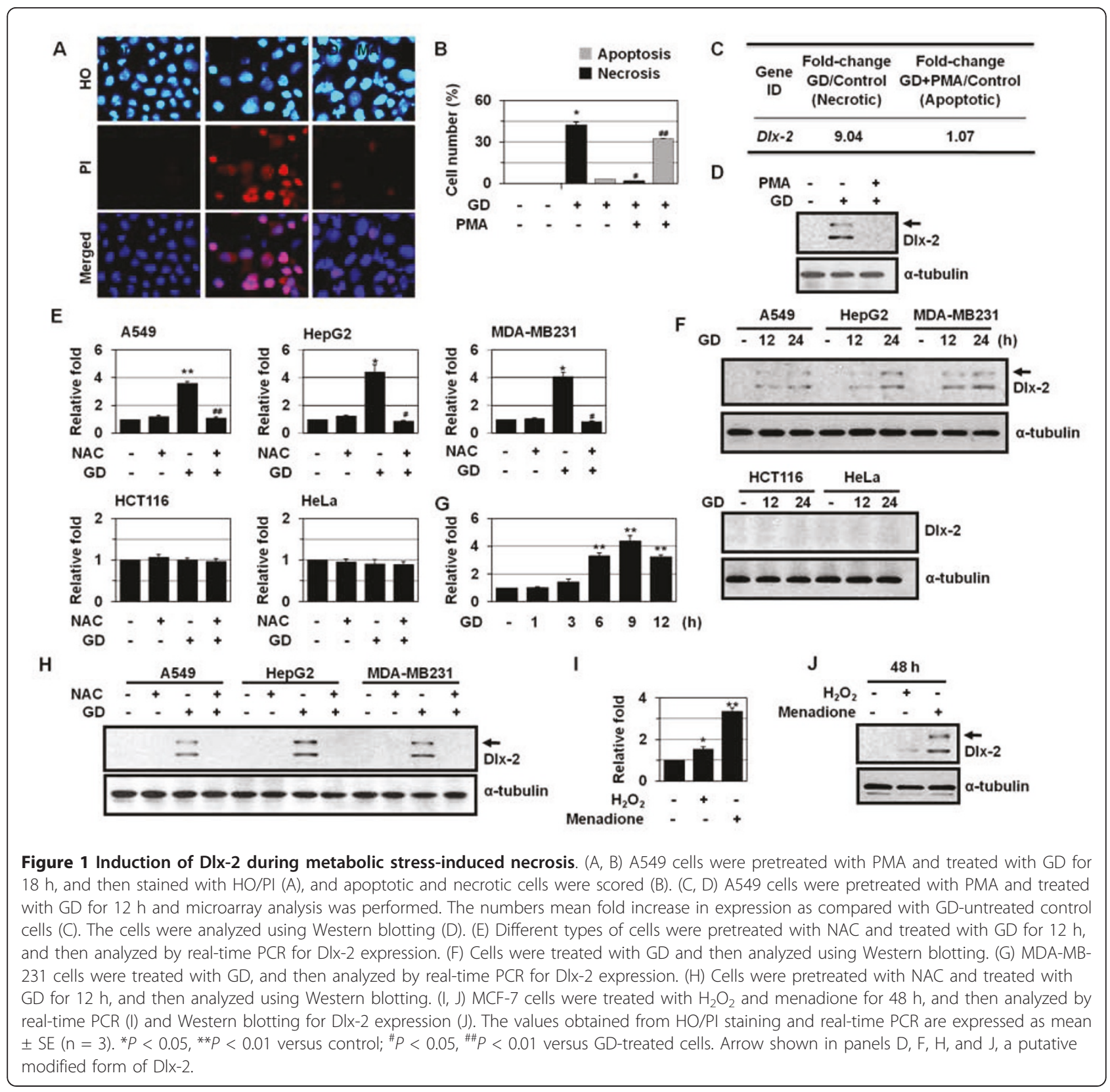

stress-induced necrosis. In two-dimensional cultures, GD can induce either apoptosis or necrosis depending on the cell types; it induces necrosis in A549, HepG2, and MDAMB-231 cells, while it induces apoptosis in HeLa and HCT116 cells [32,33]. Thus, we examined the expression of Dlx-2 in the cancer cell lines that undergo either necrosis or apoptosis upon GD treatment. Real-time quantitative PCR showed induction of Dlx-2 by GD in A549 (3.62fold), HepG2 (4.41-fold), and MDA-MB-231 cells (4.07fold), but not in HeLa and HCT116 cells (Figure 1E). Western blot analysis confirmed GD induction of Dlx-2 in A549, HepG2, and MDA-MB-231 cells but not in HeLa and HCT116 cells (Figure 1F). The induction of Dlx-2 was apparent at $6 \mathrm{~h}$ of GD, before the time point when necrosis was observed (Figure 1G). We observed that anti-Dlx-2 antibody recognized 2 bands ( $40 \mathrm{kDa}$ and $34 \mathrm{kDa}$ ) (Additional file 1. Figure S1). Both bands were increased in response to GD treatment. The lower band seems to be Dlx-2. Dlx-2 is known to be modified by phosphorylation, and therefore, the higher band is thought to be a posttranscriptionally modified form of Dlx-2. To confirm the possible modification of Dlx-2, we transfected the Dlx-2 expression vector. Dlx-2 overexpression caused morphological changes typical of cells with a mesenchymal 
phenotype in MCF-7 cells (Additional file 1. Figure S1), indicating that Dlx-2 may trigger the epithelial to mesenchymal transition that plays a key role(s) in embryonic development, wound healing, and cancer metastasis. 2 bands were recognized by anti-Dlx-2 antibody (Additional file 1. Figure S1). It remains to be elucidated whether the upper band is really a modified Dlx-2 and what mechanism is responsible for the modification and what is the biological relevance of the modification in metabolic stressinduced necrosis.

Because mitochondrial ROS especially $\mathrm{O}_{2}{ }^{-}$have been shown to mediate GD-induced cytotoxicity and necrotic cell death [34-36], we examined whether the Dlx-2 induction is linked to ROS. Dlx-2 induction by GD was inhibited by treatment with the antioxidant $\mathrm{N}$-acetylcysteine (NAC) in A549, HepG2, and MDA-MB-231 cells (Figure 1E and $1 \mathrm{H}$ ). To confirm ROS-dependent Dlx-2 induction, we treated MCF-7 cells with $\mathrm{H}_{2} \mathrm{O}_{2}$ and menadione (a $\mathrm{O}_{2}{ }^{-}$generator). Increased Dlx-2 mRNA and protein expression was observed by real-time PCR and Western blotting, respectively (Figure $1 \mathrm{I}$ and $1 \mathrm{~J}$ ). $\mathrm{O}_{2}{ }^{-}$ was a more potent inducer of Dlx-2 than $\mathrm{H}_{2} \mathrm{O}_{2}$. Similar results were obtained with MDA-MB-231 cells (data not shown). These results demonstrate the redox-sensitivity of Dlx-2 expression.

\section{Dlx-2 is induced in multicellular tumor spheroids}

We examined Dlx-2 protein expression using threedimensional multicellular tumor spheroids (MTSs). MTSs closely mimic many characteristics of poorly vascularized solid tumors, including tumor growth pattern and necrotic core formation, and hence are used for in vitro models of solid tumors. As the MTSs mature, a proliferation gradient is observed, with proliferating cells at the periphery, cell-cycle arrested cells in the inner regions, and necrotizing cells in the core regions $[37,38]$. The innermost cells die by necrosis due to insufficient supply of oxygen and glucose $[37,38]$. As demonstrated previously [33,39], MCF-7 cells form tightly packed, rounded spheroids of homogeneous size (Figure 2A). We found increased expression of Dlx-2 with extended MTS culture (Figure 2B and 2C): 2.10 -fold $(P=0.002)$ Dlx-2 induction was observed in 9-day MTSs, which may experience metabolic stress. To determine the expression of Dlx-2 in MTSs, the spheroids were selectively dissociated to yield cells from 4 discrete regions within the spheroid. Dlx-2 was detected in the inner F2 and F3 fractions and the innermost F4 fraction but not the outermost F1 fraction (Figure 2D and 2E). p27Kip1, a CKI family protein that is involved in cell cycle arrest, is regulated by HIF- $1 \alpha$, and its increased expression has been detected in the F2 and F3 fractions [40]; hence, the F2 and F3 fractions are thought to be hypoxic regions. These results indicate that Dlx-2 expression is closely related to microenvironmental stresses, such as hypoxia and GD.

\section{Dlx-2 expression in solid human tumors}

To study Dlx-2 expression in human tumors, we performed real-time PCR using the RNAs extracted from paired biopsy breast, colon, and ovarian cancer tissues and the corresponding normal tissues. Dlx-2 expression was higher in breast and ovarian cancer tissues compared with adjacent normal tissues (Additional file 2. Figure S2). In colon cancer tissues, Dlx-2 expression varied; some colon cancer tissues had high levels of Dlx-2 mRNA, whereas others had Dlx-2 mRNA levels similar to or lower than those observed in normal tissue. We also assessed the expression of Dlx-2 protein in human tumors, including breast, colon, and ovarian cancers, with immunohistochemical staining (IHC) in paraffin-embedded and formalin-fixed tissues and compared the results with those of real-time PCR analysis (Figure 3). Immunoreactivity for Dlx-2 in the tumor cells was found exclusively in the nucleus. In breast and colon cancers, Dlx-2 expression higher in tumor tissues than in matched non-tumorigenic tissues and stromal cells around cancer cells, i.e., fibroblasts and lymphocytes (Figure 3A-F). Furthermore, in ovarian cancer, Dlx-2 expression was detected in highgrade tumors that were poorly differentiated but not in the low-grade tumors, which were well differentiated (Figure 3G and 3H). Thus, Dlx-2 expression was related to poor differentiation grade of tumor, indicating a role(s) of Dlx-2 in tumor development. It is noteworthy that strong positive Dlx-2 staining was observed in tumor cells adjacent to areas of necrosis and in the cells in the necrotic core (Figure 3I and 3J). These results further support that Dlx-2 expression is related to metabolic stresses such as hypoxia and GD. However, because Dlx-2 was also expressed throughout tumor tissues, its expression is likely to be regulated also by stimuli other than metabolic stress and plays an important role(s) in tumor development.

\section{DIx-2 shRNA prevents metabolic stress-induced necrosis} in two-dimensional cell culture

We investigated whether Dlx-2 is functionally linked to GD-induced necrosis using specific transcript knockdown with short hairpin RNA (shRNA). We used 2 different shRNA oligonucleotides: one (target 1) was a 19-mer shRNA oligonucleotide directed to the N-terminal region (position from 637 to 655) of human Dlx-2 mRNA sequence [Accession No. NM_004405 GenBank: BC032558.1] and another (target 2) was a 25-mer shRNA oligonucleotide directed to the 3' UTR region (position from 1231 to 1255) of human Dlx-2 mRNA sequence [Accession No. NM_004405 GenBank: BC032558.1]. These 2 oligonucleotides were not directed to other human Dlx mRNA. Dlx-2 shRNA was verified 


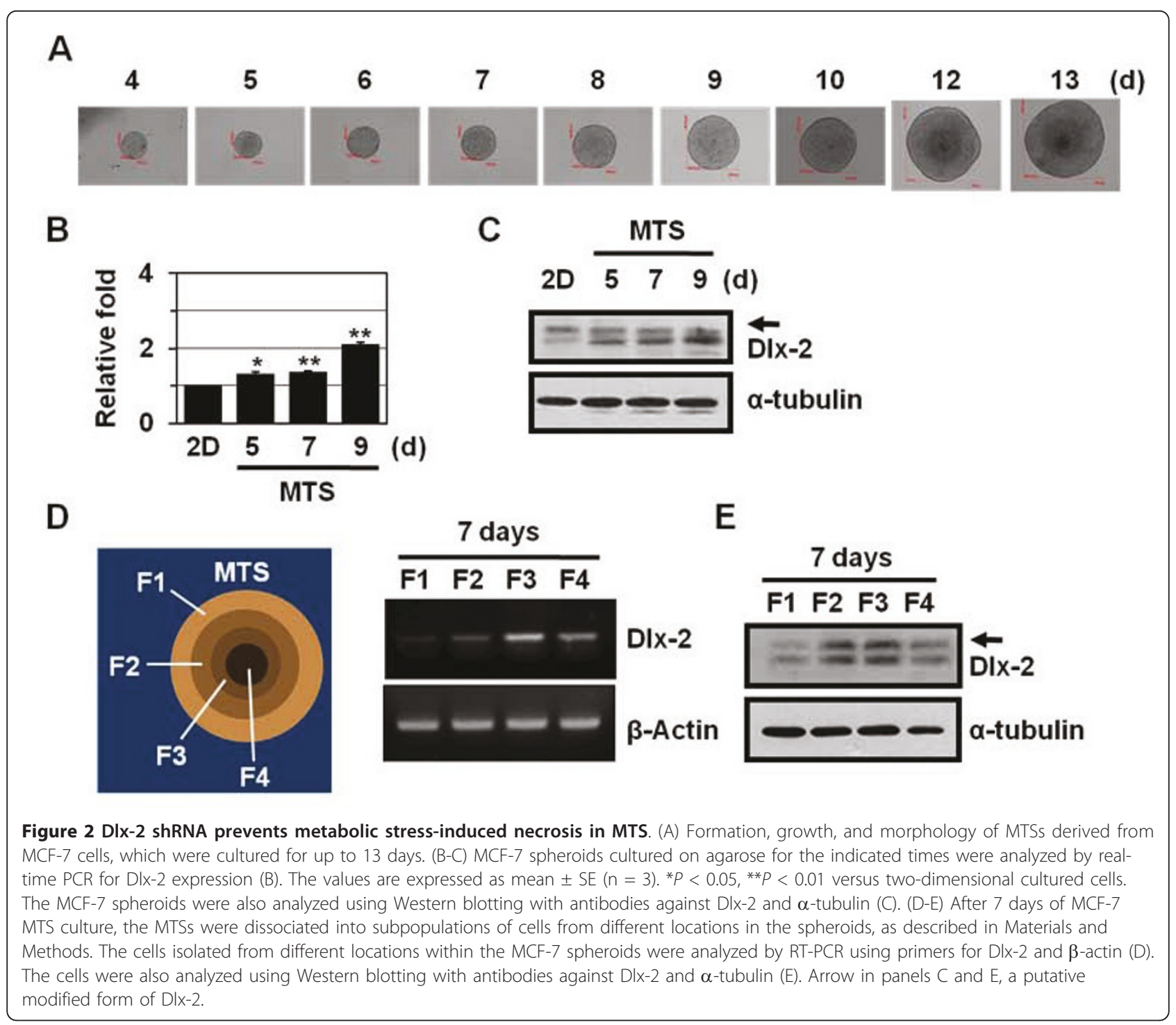

to be effective in knocking down Dlx-2 mRNA levels in A549, HepG2, and MDA-MB-231 cell lines, as determined by real-time PCR (Figure 4A, F, and 4K). Dlx-2 shRNA also prevented the GD induction of Dlx-2, as determined by Western blotting (Figure 4B, G, and 4L), thereby indicating that Dlx-2 shRNA specifically suppresses the expression and function of Dlx-2.

We examined the effects of Dlx-2 shRNA on GDinduced necrosis. Dlx-2 shRNA significantly inhibited metabolic stress-induced cell rounding (Figure $4 \mathrm{C}, \mathrm{H}$, and $4 \mathrm{M})$ and increase in cell populations that had intact pink nuclei in Hoechst 33342 (HO)/propidium iodide (PI) staining in A549, HepG2, and MDA-MB-231 cells (Figure 4D, E, I, J, N, and 4O). In A549 cells, while Dlx-2 shRNA repressed the GD-induced increase in population of PIpositive cells, it increased cells with condensed/fragmented blue nuclei (HO/PI double staining) (Figure 4D and 4E), indicating that Dlx-2 shRNA switches GD-induced necrotic cell death to apoptosis. In contrast, when GD-induced necrosis was inhibited by Dlx-2 shRNA in HepG2 and MDA-MB-231 cells, apoptosis did not occur as an alternative death mechanism (Figure 4I, J, N, and 4O). We also observed that Dlx-2 shRNA suppressed the GD-induced release of HMGB1 into the extracellular space (Figure 4P and Additional file 3. Figure S3). Dlx-2 shRNA transfection also prevented necrosis-linked lactate dehydrogenase $(\mathrm{LDH})$ release (Figure 4Q). These results indicate that Dlx-2 is implicated in metabolic stress-induced necrosis.

\section{DIx-2 shRNA prevents metabolic stress-induced necrosis in MTSs}

We examined the effects of Dlx-2 shRNA on necrosis, using MTSs. As demonstrated previously [33,39], PIpositive cells were detected in 8-9 day MTSs but not in 


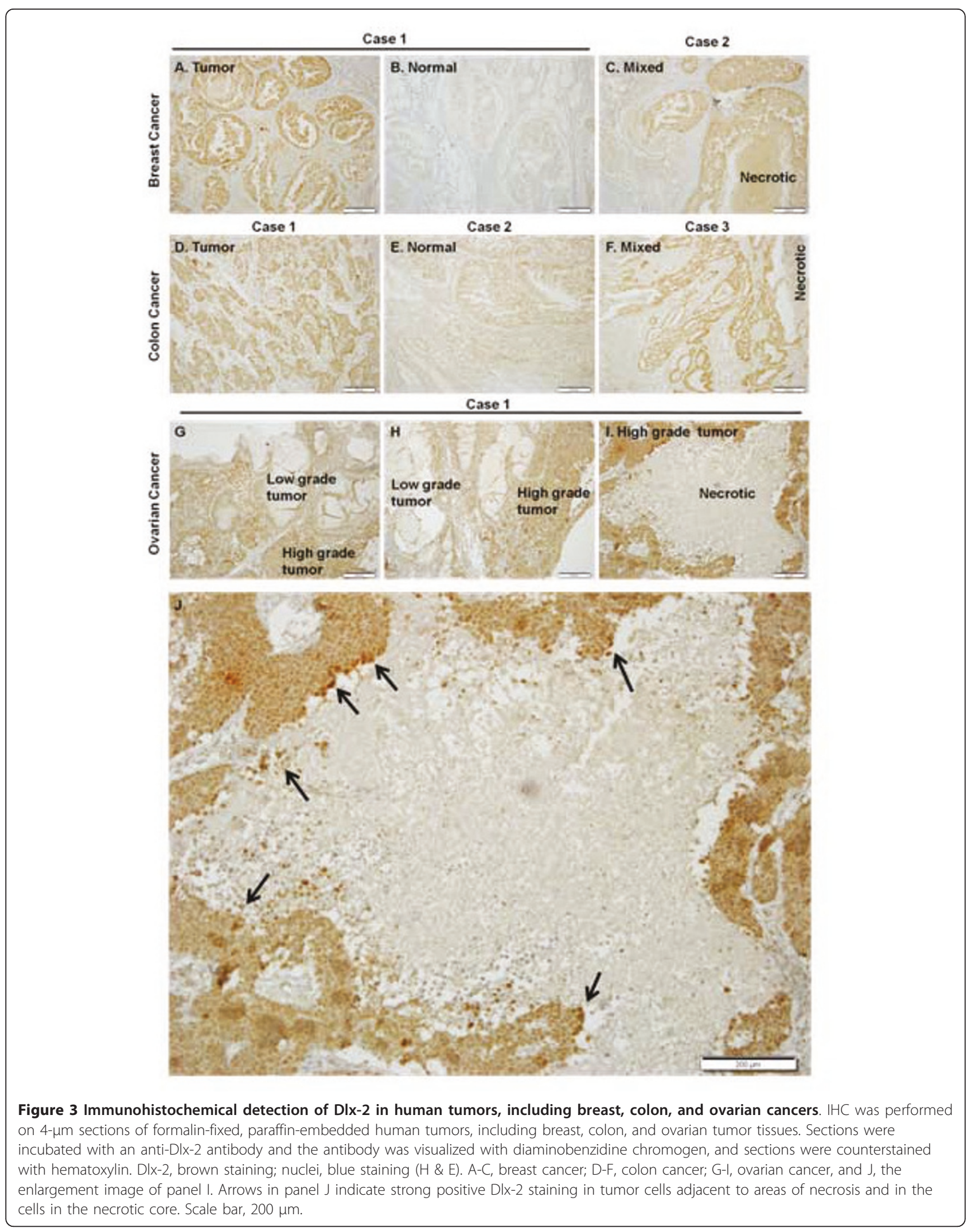




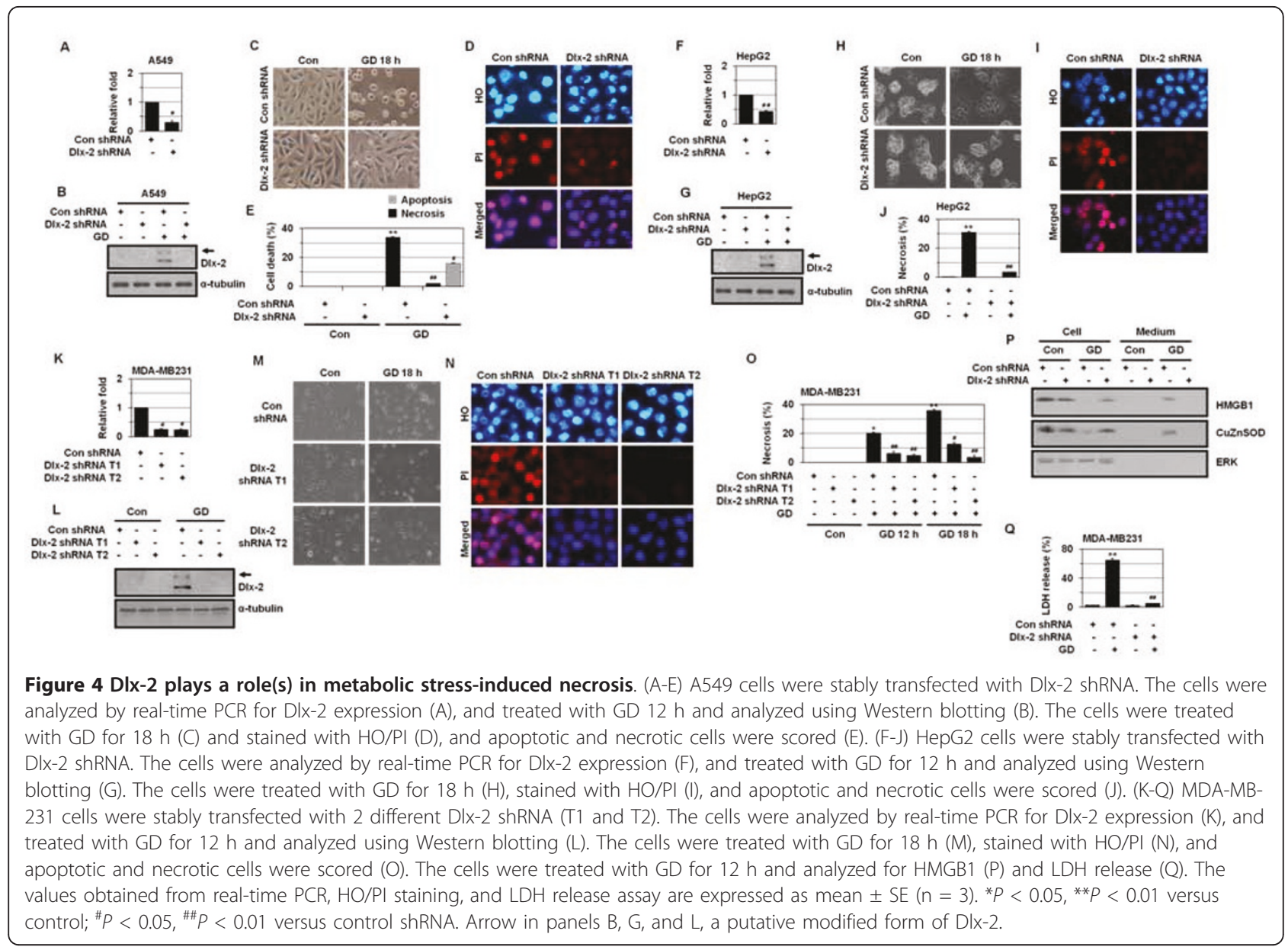

7-day MTSs (Figure 5A). Dlx-2 shRNA prevented necrosis, as revealed by a prominent reduction in the population of cells that had pink nuclei with $\mathrm{HO} / \mathrm{PI}$ staining at 8-9 days in MCF-7 MTS culture (Figure 5A and 5B). We also observed that stable Dlx-2 silencing in MCF-7 MTSs slightly suppressed the growth of the MCF-7-day MTSs (Figure 5C).

\section{DIx-2 shRNA prevents metabolic stress-induced mitochondrial ROS production, loss of mitochondrial membrane potential, and mitochondrial permeability transition}

Mitochondrial $\mathrm{O}_{2}{ }^{-}$is produced especially at Complex I or Complex III of the electron transport chain [41,42], and its levels increase upon GD treatment to mediate GDinduced cytotoxicity and cell death [34-36]. As shown in Figure 6, GD significantly enhances the production of mitochondrial ROS, $\mathrm{O}_{2}{ }^{-}$and intracellular $\mathrm{H}_{2} \mathrm{O}_{2}$, as revealed by staining with 3 different fluorogenic probes: MitoTracker Red CM- $\mathrm{H}_{2} \mathrm{XRos}$, dihydroethidium (HE), and 2 \&,7\$-dichlorofluorescein diacetate (DCFH-DA). Dlx2 interference blocked the GD-induced production of mitochondrial ROS, $\mathrm{O}_{2}{ }^{-}$and intracellular $\mathrm{H}_{2} \mathrm{O}_{2}$ (Figure 6), indicating that Dlx-2-mediated necrosis regulation is linked to its ability to control metabolic stress-induced ROS production.

ROS are known to be able to induce the mitochondrial permeability transition ( $\mathrm{MPT}$ ) pore opening in the mitochondrial inner membrane, while the transient $\mathrm{mPT}$ pore opening induces apoptosis, and its prolonged opening results in necrosis [43]. The mitochondrial membrane potential $(\triangle \Psi \mathrm{m})$ is also lost upon the $\mathrm{mPT}$ pore opening. If the $\mathrm{mPT}$ pore is open for longer periods, cells cannot generate ATP by oxidative phosphorylation, leading to necrotic cell death as a consequence of ATP depletion. Thus, we examined $\mathrm{mPT}$ by cobalt-quenched calcein (CoQC) measurement. We observed that calcein fluorescence was lost following the opening of the $\mathrm{mPT}$ pore upon GD treatment, and Dlx-2 shRNA prevented this $\mathrm{mPT}$ pore opening (Figure 7A and $7 \mathrm{~B}$ ). We also measured the $\Delta \Psi \mathrm{m}$ of cells with JC-1, a mitochondria-specific and lipophilic-cationic fluorescence dye. While red J-aggregate fluorescence appeared to be progressively lost upon GD treatment and cytoplasmic diffusion of green monomer 


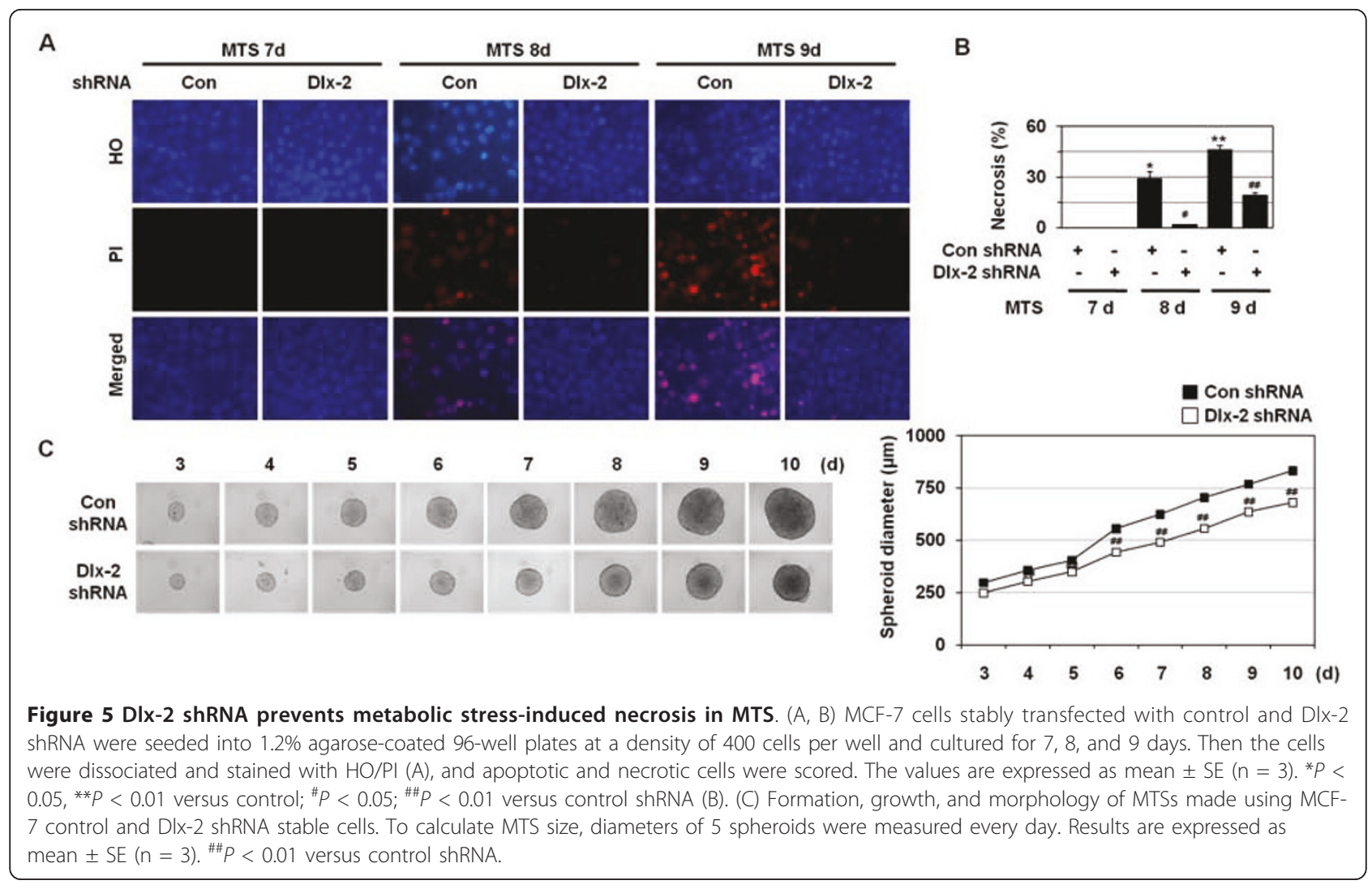

fluorescence was detected, Dlx-2 shRNA inhibited this GD-induced decline in $\Delta \Psi \mathrm{m}$ (Figure $7 \mathrm{C}$ and $7 \mathrm{D}$ ). Thus, Dlx-2 shRNA is likely to inhibit metabolic stress-induced necrosis by preventing mitochondrial ROS production and subsequent loss of mitochondrial membrane potential and mitochondrial permeability transition, which are the primary events that trigger necrosis.

\section{Discussion}

\section{Dlx-2 is implicated in necrosis}

A growing number of homeobox genes are deregulated in a variety of human tumors [20-23]. Deregulation of the expression of Dlx genes, including Dlx-4 and Dlx-5, was found in human solid tumors and hematologic malignancies and indicates an important role(s) of Dlx in tumor growth and progression [24-30]. Here, we show that Dlx2 is induced in cancer cells that die by necrosis in response to metabolic stress (Figure 1). Increased Dlx-2 expression was also detected in the inner regions, which experience metabolic stress, of human tumors (Figure 3 ) and of MTSs (Figure 2). We further found that Dlx-2 shRNA inhibited metabolic stress-induced increase in propidium iodide-positive cell populations and HMGB1 and LDH release, indicating a critical role(s) of Dlx-2 in metabolic stress-induced necrosis (Figure 4). In A549 cells, Dlx-2 shRNA repressed GD-induced increase in the population of PI-positive cells but increased the number of cells with condensed/fragmented blue nuclei (HO/PI double staining) (Figure 4D and 4E), thus indicating that Dlx-2 shRNA switches GD-induced necrotic cell death to apoptosis. In the case of HepG2 and MDA-MB-231 cells, Dlx-2 shRNA prevented necrosis but without increasing the number of apoptotic cells (Figure 4I, J, N, and 4O). Previously, we showed that pretreatment of the anti-oxidant NAC switched GD-induced necrosis to apoptosis in A549 cells, whereas it switched it to autophagy-like cell death in HepG2 and MDA-MB-231 cells [44]. Thus, Dlx2 shRNA-transfected cells can undergo either apoptosis or other cell fates (including autophagic cell death) upon $\mathrm{GD}$, depending on the cell types due to their different cellular context.

Although Dlx-2 shRNA inhibited metabolic stressinduced necrosis, Dlx-2 overexpression did not trigger necrosis, although it caused an alteration in cell morphology to the mesenchymal cell-like phenotype (Additional file 1. Figure S1C), indicating that Dlx-2 is necessary but not sufficient for metabolic stress-induced necrosis. In agreement with this observation, Dlx-2 was expressed throughout tumor tissues (Figure 3), indicating that its expression is also regulated by stimuli other than metabolic stress. Necrosis is accompanied by several different processes, including mitochondrial dysfunction, excess 


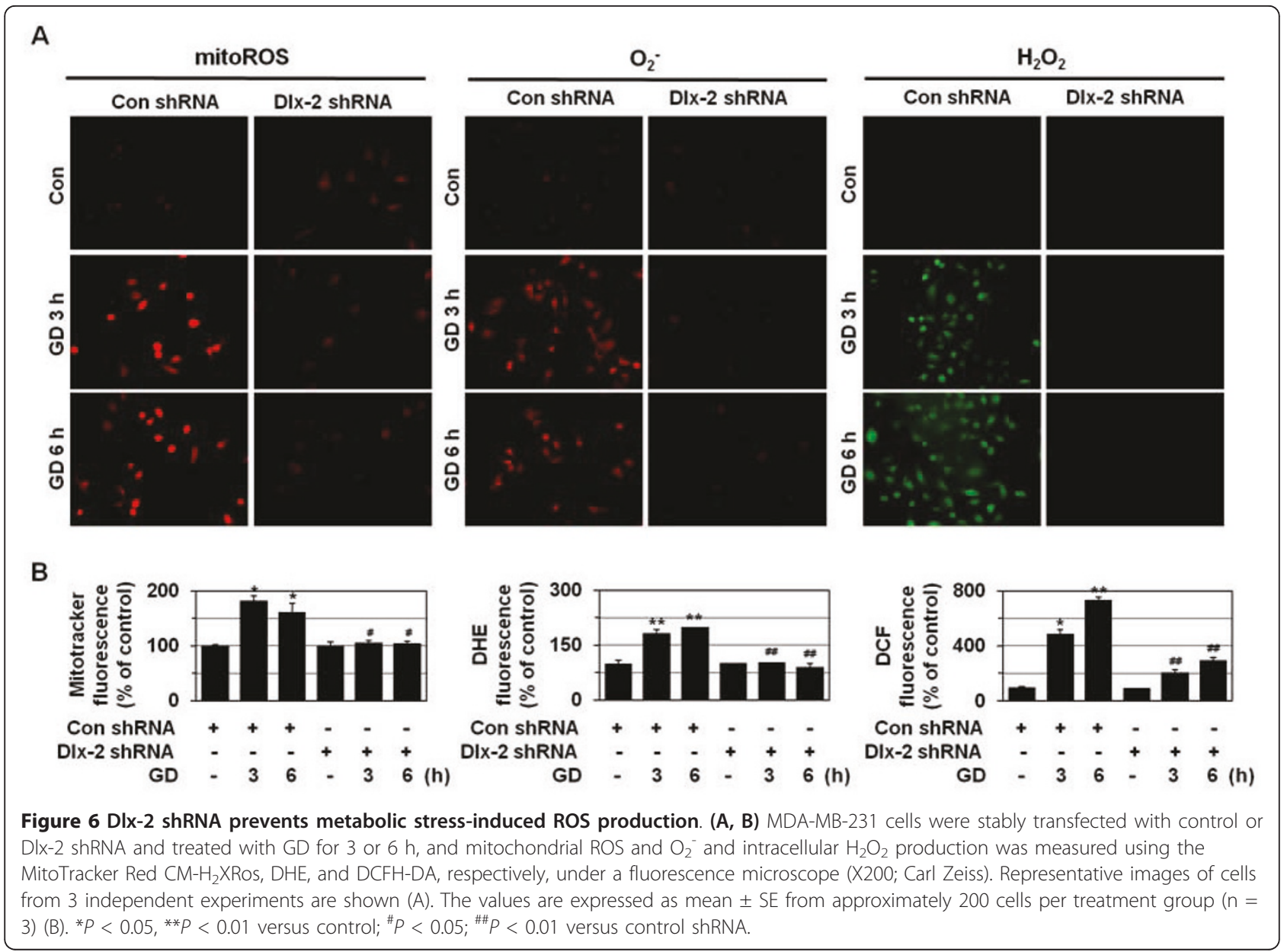

ROS production, and ATP depletion [6,7]. Thus, Dlx-2 may trigger necrosis if tumor cells are under such a metabolic stress environment. In other words, in the absence of metabolic stress, Dlx-2 may promote tumor growth and progression by unknown mechanisms, but in the presence of metabolic stress, it may facilitate metabolic stressinduced necrosis by promoting mitochondrial ROS production. Our results suggest that Dlx-2 may be implicated in tumor progression via the regulation of metabolic stress-induced necrosis.

\section{Regulation of cellular redox status by Dlx-2}

Our results showed that GD-induced expression of Dlx-2 is ROS-dependent (Figure 1), and GD-induced production of ROS is also Dlx-2-dependent (Figure 6). ROS produced under stress conditions are known to spread from one mitochondrion to neighboring mitochondria in a process known as ROS-induced ROS release (RIRR) for enhanced ROS production, $[45,46]$. Dlx-2 induced upon metabolic stress may facilitate ROS production, which in turn enhance Dlx-2 expression to accelerate massive ROS production by RIRR and induce GD-induced cytotoxicity and necrosis, thereby constituting a positive feedback mechanism between Dlx-2 expression and cellular ROS levels. Mitochondrial ROS massively produced through RIRR may oxidize HMGB1 released by necrosis and the oxidized HMGB1 may exert its activity to trigger apoptosis. However, because many proapoptotic molecules such as p53 and caspases are aggregated to an inactive form upon GD treatment [44], GD is likely to induce necrosis instead of apoptosis.

How does Dlx-2 control mitochondrial ROS production in response to GD? Mitochondrial $\mathrm{O}_{2}{ }^{-}$is produced even under normal conditions $[41,42]$, and its production is enhanced by GD treatment and triggers necrotic cell death. Mitochondrial dysfunction has been linked to the induction of necrosis. Tumor cells have been shown to have abnormal mitochondrial structure and DNA integrity $[47,48]$, and these mitochondrial deregulations have been suggested to make tumor cells more sensitive to oxidative stress and cell killing induced by GD and 2-deoxyglucose, a glycolysis inhibitor [36]. In addition, tumor cells with dysregulated mitochondria undergo necrosis instead of apoptosis in response to alkylating DNA damage that 
A
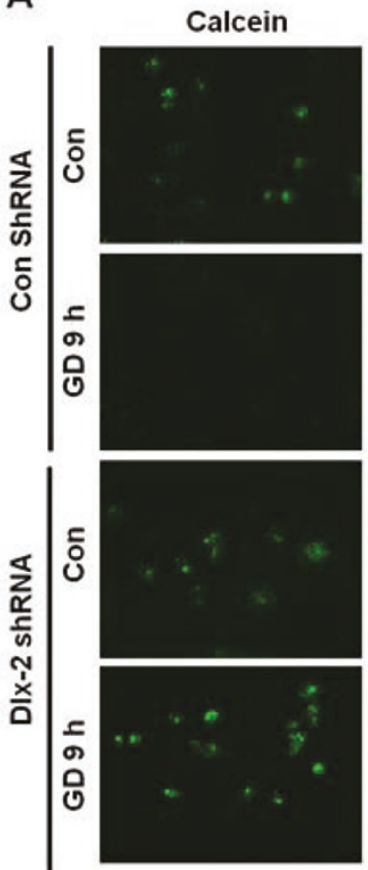

B

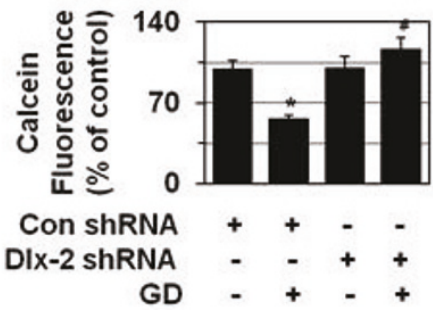

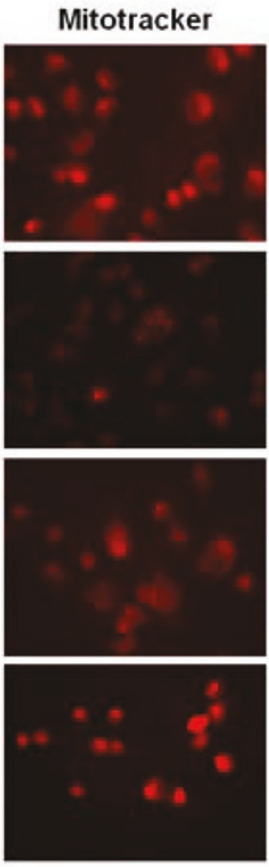
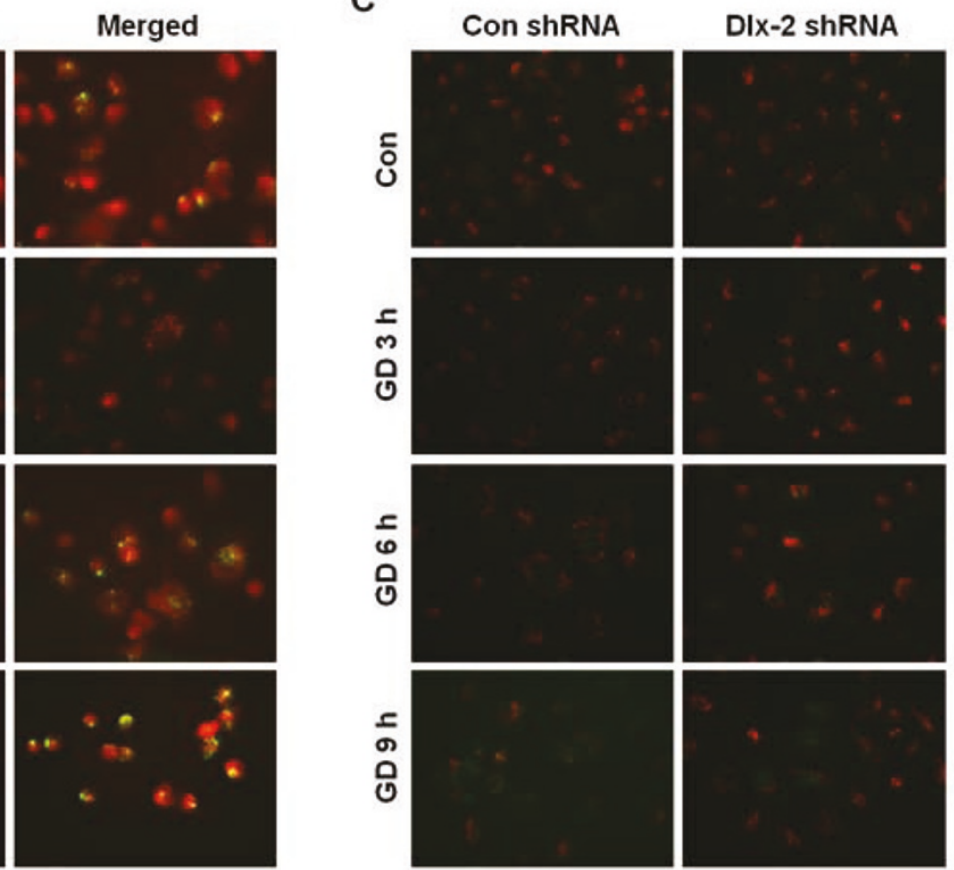

D

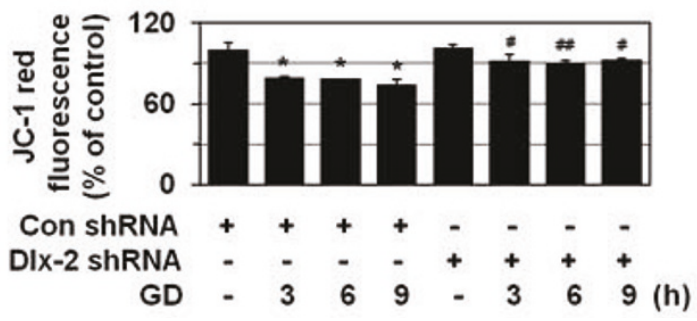

Figure 7 Dlx-2 shRNA prevents metabolic stress-induced loss of $\Delta \Psi \mathrm{m}$ and $\mathrm{mPT}$. (A, B) MDA-MB-231 cells were stably transfected with control or Dlx-2 shRNA and treated with GD for $9 \mathrm{~h}$ and loaded with $0.5 \mu \mathrm{M}$ calcein $\mathrm{AM}$ and $5 \mathrm{mM} \mathrm{CoCl}_{2}$ for the final 15 min of the incubation. To detect cytoplasmic mitochondrial distribution, $50 \mathrm{nM}$ MitoTracker CMX-ROS were added during calcein loading. Calcein fluorescence was excited at $488 \mathrm{~nm}$ and emitted at $515 \mathrm{~nm}$; MitoTracker Red CMX-ROS was excited at $579 \mathrm{~nm}$, and emitted at $599 \mathrm{~nm}$; and the cells were observed using fluorescence microscopy. Representative images of cells from 3 independent experiments were shown (A). The results are expressed as mean \pm SE from 15 to 30 cells per treatment group $(n=3)(B) .{ }^{*} P<0.05$ versus control; ${ }^{*} P<0.01$ versus control shRNA. (C, D) MDA-MB-231 cells stably transfected with control or Dlx-2 shRNA were treated with GD for the indicated times and then treated with $5 \mathrm{mg} / \mathrm{ml}$ JC-1 for 15 min. Representative images of cells from 3 independent experiments are shown (C). The results are expressed as mean \pm SE from 50 to 100 cells per group $(n=3)(\mathrm{D}) .{ }^{*} P<0.05$ versus control; ${ }^{*} P<0.05$; ${ }^{\# \#} P<0.01$ versus control shRNA.

induces rapid ATP depletion through PARP activation [49]. We speculate that Dlx-2 may affect mitochondrial function and sensitize tumor cells to metabolic stress and death by necrosis. HMGB1 is known to enhance the activities of a number of transcription factors, including p53 and the Rel/NF- $\kappa$ B family. Our preliminary data showed that HMGB1 shRNA prevents metabolic stress-induced necrosis (data not shown). These results indicate that HMGB1 may be implicated in Dlx-2-mediated necrosis. We are investigating if Dlx-2 regulates metabolic stressinduced necrosis by affecting mitochondrial function and if HMGB1 plays a role(s) in Dlx-2-mediated necrosis.

\section{Conclusion}

Necrosis promotes tumor progression and aggressiveness. Consequently, necrosis has important clinical implications in tumor development, but its molecular mechanism has been less investigated. In this study, we show that Dlx-2, a homeobox gene of the Dlx family that is involved in embryonic development, is implicated in metabolic stressinduced necrosis via the regulation of metabolic stressinduced increases in mitochondrial ROS, which are responsible for triggering necrosis. These results suggest that Dlx-2 may be implicated in tumor progression via the regulation of metabolic stress-induced necrosis. 


\section{Materials and methods}

\section{Cell culture, chemical treatment, and MTS culture}

A549, MDA-MB-231, HepG2, HCT116, and HeLa cells were obtained from American Type Culture Collection, maintained in RPMI-1640 or DMEM supplemented with $10 \%(\mathrm{v} / \mathrm{v})$ heat-inactivated fetal bovine serum (HyClone, Logan, UT) and 1\% penicillin-streptomycin (HyClone, Logan, UT) in a $37^{\circ} \mathrm{C}$ humidified incubator with $5 \% \mathrm{CO}_{2}$, and treated with GD [32]. To induce GD-induced necrosis-to-apoptotis switch in A549 cells, the cells were pretreated with $100 \mathrm{nM}$ PMA for $30 \mathrm{~min}$ and treated with GD. NAC (10 mM) was pretreated for $1 \mathrm{~h}$ and treated with GD. $\mathrm{H}_{2} \mathrm{O}_{2}(300 \mu \mathrm{M})$ and menadione $(10 \mu \mathrm{M})$ were treated to cells for $48 \mathrm{~h}$. For the MTS culture, MCF-7 cells (provided by Dr. JI Yook, University of Yonsei, Korea) were seeded at a density of 400 cells in $200 \mu \mathrm{l}$ medium into $1.2 \%$ agarose-precoated 96 -well plates. After 3 days of culture, $100 \mu$ l of medium was replaced with fresh medium every 2 days. To determine the MTS growth, the diameters of spheroids were measured every day. For analysis of cell death patterns, MTSs were trypsinized and then stained with $\mathrm{HO} / \mathrm{PI}$ as described below. To determine the expression of Dlx-2 within MTSs, MTSs were dissociated into subpopulations of cells from 4 different locations in the spheroid as described by LaRue et al. [40]. The cells isolated from different locations within spheroids were analyzed by Western blotting, reverse transcription-polymerase chain reaction (RT-PCR), and real-time PCR as described below.

\section{Microarray}

Microarrays were performed to screen for the differentially expressed genes using Operon Human Whole $35 \mathrm{~K}$ Oligo chips (GenoCheck, Korea); a complete listing of the genes on this microarray is available at the web site: http://www.genocheck.com. Data analysis was carried out using GeneSpring GX 7.3 (Agilent Technologies), and the values were normalized using the LOWESS algorithm. The Affymetrix microarray data have been deposited in the Gene Expression Omnibus (GEO) database (GEO accession no. GSE24271).

\section{Western blotting, HMGB1 release assay, LDH release assay, RT-PCR, and real-time PCR}

Western blotting analyses were performed as described previously using the following antibodies: Dlx-2 (Chemicon, France), $\alpha$-tubulin (Biogenex, CA), HMGB1 (BD Pharmingen, CA), CuZnSOD, (Santa Cruz, CA), ERK1/2 (Cell Signaling, MA) [32]. A HMGB1 release assay was carried out as described previously [32]. LDH release was measured using the LDH Cytotoxicity Detection Kit (Roche Applied Science) according to the manufacturer's instructions. Transcript levels were assessed with RT-
PCR and quantitative real-time PCR with primers for Dlx-2 and $\beta$-actin (Additional file 4. Table S1).

\section{$\mathrm{HO} / \mathrm{PI}$ staining, immunofluorescence, and confocal microscopy}

GD-induced cell death mode was determined by $\mathrm{HO} / \mathrm{PI}$ double staining as described previously [32]. HO crosses the plasma membrane of all cells that are viable or damaged, resulting in blue fluorescence, whereas PI only penetrates cells with damaged membranes, leading to nuclear red fluorescence. Thus, intact blue nuclei, condensed/fragmented blue nuclei, condensed/fragmented pink nuclei, and intact pink nuclei were considered to indicate viable, early apoptotic, late apoptotic (secondary necrotic), and necrotic cells, respectively. Apoptotic and necrotic cells were scored using 500 to 800 cells per group $(\mathrm{n}=3)$. Intracellular $\mathrm{H}_{2} \mathrm{O}_{2}, \mathrm{O}_{2}{ }^{-}$, and mitochondrial ROS were detected using the DCFH-DA (Molecular Probes; $50 \mu \mathrm{M}$ ), HE (Molecular Probes; $10 \mu \mathrm{M}$ ), and MitoTracker Red CM- $\mathrm{H}_{2}$ XRos (Molecular Probes, $50 \mathrm{nM}$ ), respectively, by fluorescence microscopy. Next, $\mathrm{mPT}$ pore opening and $\Delta \Psi \mathrm{m}$ were analyzed using CoQC and JC-1 staining, respectively, as described previously [33]. Fluorescence intensity was analyzed with Axiovision LE software (Release 4.8 version).

\section{DIx-2 transfection and shRNA interference}

pCAGGS-Dlx-2 (provided by Dr. John L.R. Rubenstein, University of California at San Francisco) was constructed by inserting the Dlx-2 open reading frame into pCAGGS (BCCM/LMPD, Belgium). The vectors pCAGGS and pCAGGS-Dlx-2 were transfected into MCF-7 using jetPEI (Polyplus transfection) according to manufacturer's protocol. pSUPER-Dlx-2 shRNA was generated from 2 different annealed oligonucleotides (target 1, 5'-GATCCCCTTCGGATAGTGAACGGGAATTCAAGAGATTCCCGTTCACTATCCGAATTTTTA-3' and 5'-AGCTTAAAAATT CGGATAGTGAACGGGAATCTCTTGAATTCCCGTTCACTATCCGAAGGG-3' and target 2, 5' - $\overline{\text { GATCCCCA- }}$ GAGACCACTTATCC TCATTGCTTATTCAAGAGATAAGCAA TGAGGATAAGTGGTCTCT.

TTTTTA - 3' and 5' AGCTTAAAAAAGAGACCA CTTATCCTCATTGCTTATCTCTTGAATAAGCAATGAGGATA AGTGGTCTCTGGG-3') [Accession No. GenBank: ] that were inserted into the HindIII and BglII sites of pSUPER.gfp/neo (Oligoengine Platform, Seattle, WA); the human Dlx-2 target sequence is underlined. Control shRNA was generated from annealed oligonucleotides (5'-GATCCCCAATTCTCCGAACGTGTCACGTTTCAAGAGAACGTGACACGTTCGGAGA ATTTTTTTA-3' and 5'-AGCTTAAAAAAATTCTCCGAACGTGTCACGTTCTCTTGAAAC $\overline{\text { GTGACACG }}$ TTCGGAGAATTGGG-3') inserted into the HindIII and BglII sites of pSUPER.gfp/neo (Oligoengine Platform, 
Seattle, WA). All target sequences were designed and verified as specific for Dlx-2 by BLAST searching against the human genome and real-time PCR, respectively. The vectors pSUPER-control and pSUPER-Dlx-2 shRNA were transfected using jetPEI, and stable cell line selection performed with 1-2 mg/ml G418. Several clones were isolated after shRNA transfection in each cell type and individually characterized.

\section{Real-time analysis and immunohistochemical staining for Dlx-2 expression in human cancer issues}

The expression of the Dlx-2 gene in normal and cancerous human tissues was estimated by real-time PCR. Frozen cancer and normal matched tissue pairs from the same individuals were provided by the National Biobank of Korea, PNUH. For RNA extraction, tissues were added to $1 \mathrm{ml}$ of Trizol reagent (Invitrogen, NY) and vortexed twice for $10 \mathrm{~s}$ each time, using the FastPrep-24 system (MP Biomedicals LLC.). After vortexing, tissue lysates were quick chilled on ice, and then the procedure was continued in accordance with the manufacturer's protocol. Isolated $2 \mu \mathrm{g}$ of total RNA were used as the template, and reverse transcription was performed in the presence of M-MLV reverse transcriptase (Invitrogen), $5 \times$ first strand buffer, RNase inhibitor, oligo (dT)20, dNTP, and DTT, according to manufacturer's protocol using Thermal Block (MyGenie96, Bioneer, Korea).

IHC was performed on 4- $\mu \mathrm{m}$ sections of formalin-fixed, paraffin-embedded human cancer tissues (Department of Pathology, College of Medicine, Chosun University). Sections were deparaffinized in xylene and graded alcohol. Antigen retrieval was performed by autoclaving for 15 min. After incubation with blocking solution for $30 \mathrm{~min}$, sections were incubated with anti-Dlx-2 antibody for $1 \mathrm{~h}$, biotinylated secondary antibody for $20 \mathrm{~min}$, and then with streptavidin horseradish peroxidase for $10 \mathrm{~min}$. Staining was carried out with diaminobenzidine chromogen and counterstaining with hematoxylin.

\section{Statistical analysis}

All experiments were independently performed at least 3 times. Data were analyzed by the Student's $t$-test and $P<0.05$ was considered statistically significant.

\section{Additional material}

Additional file 1: Figure S1. Full scan blots. (A) Full scan of blot depicted in Figure 1D. A549 cells were pretreated with PMA (100 nM) for 30 min and treated with GD for $12 \mathrm{~h}$. The cells were analyzed using Western blotting with antibodies against Dlx-2 and $\alpha$-tubulin $(10 \mu \mathrm{g}$ protein extract). (B) Full scan of blot depicted in Figure 1F. A549, HepG2, MDA-MB-231, HCT116, and HeLa cells were treated with GD for the indicated times and then analyzed using Western blotting with antibodies against Dlx-2 and $\alpha$-tubulin (10 $\mu \mathrm{g}$ protein extract). (C) MCF-7 cells were transiently transfected with a control or Dlx-2 expression vector for $2 \mathrm{~d}$ and cell morphology was examined using phase-contrast microscopy and photographed under a magnification of $400 \times$. Dlx-2 expression was analyzed using Western blotting with antibodies against Dlx-2 and $\alpha$-tubulin. Arrow, a putative modified form of Dlx-2.

Additional file 2: Figure S2. Real-time PCR analysis for expression of DIx-2 in human tumors, including breast, colon, and ovarian cancers. Dlx-2 expression was analyzed with real-time PCR using the RNAs extracted from paired biopsy breast, colon, and ovarian cancer tissues and the corresponding normal tissues. Values are normalized to $\beta$-actin. ${ }^{*} P<$ $0.05,{ }^{* *} P<0.01$ versus normal tissues. $N$, normal tissues; $T$, tumors.

Additional file 3: Figure S3. Ponceau S staining pattern of Figure 4P. MDA-MB-231 cells that were stably transfected with control or Dlx-2 shRNA were treated with GD for $12 \mathrm{~h}$, and both medium and cell pellets were prepared and analyzed with SDS-PAGE and Ponceau $S$ staining.

Additional file 4: Table S1. Primer sequences for RT-PCR and real time PCR.

\section{Abbreviations}

CoQC: cobalt-quenched calcein; CuZnSOD: copper-zinc superoxide dismutase; Dll: Drosophila distal-less; Dlx: Distal-less; GD: glucose deprivation; HMGB1: high mobility group box 1; IHC: immunohistochemistry; IL-1a: interleukin-1a; ROS: reactive oxygen species; $\triangle \Psi \mathrm{m}$ : mitochondrial membrane potential; MnSOD: manganese superoxide dismutase; $\mathrm{MPT}$ : mitochondrial permeability transition; MTSs: multicellular tumor spheroids; NAC: Nacetylcysteine; PMA: phorbol-12-myristate-13-acetate; RAGEs: receptor for advanced glycation end products; RIRR: ROS-induced ROS release; shRNA: short hairpin RNA; TLR: Toll-like receptor.

\section{Acknowledgements}

This study was supported by a grant of the Korea Healthcare technology R\&D Project, Ministry for Health, Welfare, Republic of Korea (A080303).

\section{Author details}

${ }^{1}$ Department of Molecular Biology, College of Natural Sciences, Pusan National University, Pusan 609-735, Korea. ${ }^{2}$ Nanobiotechnology Center, Pusan National University, Pusan 609-735, Korea. ${ }^{3}$ Research Center for Resistant Cells, College of Medicine, Chosun University, Gwangju 501-759, Korea. ${ }^{4}$ Department of Pathology, College of Medicine, Chosun University, Gwangju 501-759, Korea. ${ }^{5}$ DNA Identification Center, National Forensic Service, Seoul 158-707, Korea.

\section{Authors' contributions}

SYL performed most of the experiments and participated in designing the study, analyzing the data, and drafting the manuscript. HMJ designed and performed the experiments and participated in analyzing the data and drafting the manuscript, MKJ, CHK, and HSB performed the experiments, HGP and S-CL analyzed the data, SIH performed the experiments and analyzed the data and drafting the manuscript. HSK conceptualized the study, participated in its design, and helped analyze the data and draft the manuscript.

All authors read and approved the final manuscript.

\section{Competing interests}

The authors declare that they have no competing interests.

Received: 17 April 2011 Accepted: 14 September 2011 Published: 14 September 2011

\section{References}

1. Tomes L, Emberley E, Niu Y, Troup S, Pastorek J, Strange K, Harris A, Watson PH: Necrosis and hypoxia in invasive breast carcinoma. Breast Cancer Res Treat 2003, 81:61-69.

2. Kunz M, Ibrahim SM: Molecular responses to hypoxia in tumor cells. Mol Cancer 2003, 2:23.

3. Gatenby RA, Gillies RJ: Why do cancers have high aerobic glycolysis? Nat Rev Cancer 2004, 4:891-899.

4. Jin S, DiPaola RS, Mathew R, White E: Metabolic catastrophe as a means to cancer cell death. J Cell Sci 2007, 120:379-383. 
5. Jin S, White E: Role of autophagy in cancer: management of metabolic stress. Autophagy 2007, 3:28-31.

6. Zong WX, Thompson CB: Necrotic death as a cell fate. Genes Dev 2006, 20:1-15.

7. Golstein P, Kroemer G: Cell death by necrosis: towards a molecular definition. Trends Biochem Sci 2007, 32:37-43.

8. Vakkila J, Lotze MT: Inflammation and necrosis promote tumour growth. Nat Rev Immunol 2004, 4:641-648.

9. Grivennikov SI, Greten FR, Karin M: Immunity, inflammation, and cancer. Cell 2010, 140:883-899.

10. Hanahan D, Weinberg RA: Hallmarks of cancer: the next generation. Cell 2011, 144:646-674

11. Lotze MT, Tracey KJ: High-mobility group box 1 protein (HMGB1): nuclear weapon in the immune arsenal. Nat Rev Immunol 2005, 5:331-342.

12. Schlueter $C$, Weber $H$, Meyer B, Rogalla P, Roser K, Hauke S, Bullerdiek J: Angiogenetic signaling through hypoxia: HMGB1: an angiogenetic switch molecule. Am J Pathol 2005, 166:1259-1263.

13. Taguchi A, Blood DC, del Toro G, Canet A, Lee DC, Qu W, Tanji N, Lu Y, Lalla E, Fu C, et al: Blockade of RAGE-amphoterin signalling suppresses tumour growth and metastases. Nature 2000, 405:354-360.

14. Kang R, Livesey KM, Zeh HJ, Loze MT, Tang D: HMGB1: a novel Beclin 1binding protein active in autophagy. Autophagy 2010, 6:1209-1211.

15. Tang D, Kang R, Cheh CW, Livesey KM, Liang X, Schapiro NE, Benschop R, Sparvero LJ, Amoscato AA, Tracey KJ, et al: HMGB1 release and redox regulates autophagy and apoptosis in cancer cells. Oncogene 2010, 29:5299-5310.

16. Tang D, Kang R, Zeh HJ, Lotze MT: High-mobility group box 1 and cancer. Biochim Biophys Acta 2010, 1799:131-140.

17. Merlo GR, Zerega B, Paleari L, Trombino S, Mantero S, Levi G: Multiple functions of Dlx genes. Int J Dev Biol 2000, 44:619-626.

18. Panganiban G, Rubenstein JL: Developmental functions of the Distal-less/ Dlx homeobox genes. Development 2002, 129:4371-4386.

19. Kraus $P$, Lufkin T: Dlx homeobox gene control of mammalian limb and craniofacial development. Am J Med Genet A 2006, 140:1366-1374.

20. Abate-Shen C: Deregulated homeobox gene expression in cancer: cause or consequence? Nat Rev Cancer 2002, 2:777-785.

21. Samuel S, Naora H: Homeobox gene expression in cancer: insights from developmental regulation and deregulation. Eur J Cancer 2005, 41:2428-2437.

22. Hennessy BT, Mills GB: Ovarian cancer: homeobox genes, autocrine/ paracrine growth, and kinase signaling. Int J Biochem Cell Biol 2006, 38:1450-1456.

23. Argiropoulos B, Humphries RK: Hox genes in hematopoiesis and leukemogenesis. Oncogene 2007, 26:6766-6776.

24. Hara F, Samuel S, Liu J, Rosen D, Langley RR, Naora H: A homeobox gene related to Drosophila distal-less promotes ovarian tumorigenicity by inducing expression of vascular endothelial growth factor and fibroblast growth factor-2. Am J Pathol 2007, 170:1594-1606.

25. Man YG, Fu SW, Schwartz A, Pinzone JJ, Simmens SJ, Berg PE: Expression of BP1, a novel homeobox gene, correlates with breast cancer progression and invasion. Breast Cancer Res Treat 2005, 90:241-247.

26. Tan Y, Timakhov RA, Rao M, Altomare DA, Xu J, Liu Z, Gao Q, Jhanwar SC, Di Cristofano A, Wiest DL, et al: A novel recurrent chromosomal inversion implicates the homeobox gene Dlx5 in T-cell lymphomas from Lck-Akt2 transgenic mice. Cancer Res 2008, 68:1296-1302.

27. Tan Y, Cheung M, Pei J, Menges CW, Godwin AK, Testa JR: Upregulation of DLX5 promotes ovarian cancer cell proliferation by enhancing IRS-2-AKT signaling. Cancer Res 2010, 70:9197-9206.

28. Kato T, Sato N, Takano A, Miyamoto M, Nishimura H, Tsuchiya E, Kondo S, Nakamura Y, Daigo Y: Activation of placenta-specific transcription factor distal-less homeobox 5 predicts clinical outcome in primary lung cancer patients. Clin Cancer Res 2008, 14:2363-2370.

29. Morini M, Astigiano S, Gitton Y, Emionite L, Mirisola V, Levi G, Barbieri O: Mutually exclusive expression of DLX2 and DLX5/6 is associated with the metastatic potential of the human breast cancer cell line MDA-MB231. BMC Cancer 2010, 10:649.

30. Xu J, Testa JR: DLX5 (distal-less homeobox 5) promotes tumor cell proliferation by transcriptionally regulating MYC. J Biol Chem 2009, 284:20593-20601.
31. Shimamoto T, Nakamura S, Bollekens J, Ruddle FH, Takeshita K: Inhibition of DLX-7 homeobox gene causes decreased expression of GATA-1 and c-myc genes and apoptosis. Proc Natl Acad Sci USA 1997, 94:3245-3249.

32. Kim CH, Han SI, Lee SY, Youk HS, Moon JY, Duong HQ, Park MJ, Joo YM, Park HG, Kim YJ, et al: Protein kinase C-ERK1/2 signal pathway switches glucose depletion-induced necrosis to apoptosis by regulating superoxide dismutases and suppressing reactive oxygen species production in A549 lung cancer cells. J Cell Physiol 2007, 211:371-385.

33. Kim CH, Jeon HM, Lee SY, Ju MK, Moon JY, Park HG, Yoo MA, Choi BT, Yook JI, Lim SC, et al: Implication of Snail in Metabolic Stress-induced Necrosis. PLoS One 2011

34. Ahmad IM, Aykin-Burns N, Sim JE, Walsh SA, Higashikubo R, Buettner GR, Venkataraman S, Mackey MA, Flanagan SW, Oberley LW, Spitz DR: Mitochondrial $\mathrm{O}_{2}^{*}$ - and $\mathrm{H} 2 \mathrm{O} 2$ mediate glucose deprivation-induced stress in human cancer cells. J Biol Chem 2005, 280:4254-4263.

35. Spitz DR, Sim JE, Ridnour LA, Galoforo SS, Lee YJ: Glucose deprivationinduced oxidative stress in human tumor cells. A fundamental defect in metabolism? Ann N Y Acad Sci 2000, 899:349-362.

36. Aykin-Burns N, Ahmad IM, Zhu Y, Oberley LW, Spitz DR: Increased levels of superoxide and $\mathrm{H} 2 \mathrm{O} 2$ mediate the differential susceptibility of cancer cells versus normal cells to glucose deprivation. Biochem J 2009, 418:29-37.

37. Horning JL, Sahoo SK, Vijayaraghavalu S, Dimitrijevic S, Vasir JK, Jain TK, Panda AK, Labhasetwar V: 3-D tumor model for in vitro evaluation of anticancer drugs. Mol Pharm 2008, 5:849-862.

38. Ivascu A, Kubbies M: Diversity of cell-mediated adhesions in breast cancer spheroids. Int J Oncol 2007, 31:1403-1413.

39. Jeong EK, Lee SY, Jeon HM, Ju MK, Kim CH, Kang HS: Role of extracellular signal-regulated kinase (ERK) $1 / 2$ in multicellular resistance to docetaxel in MCF-7 cells. Int J Oncol 2010, 37:655-661.

40. LaRue KE, Khalil M, Freyer JP: Microenvironmental regulation of proliferation in multicellular spheroids is mediated through differential expression of cyclin-dependent kinase inhibitors. Cancer Res 2004, 64:1621-1631.

41. Adam-Vizi V, Chinopoulos C: Bioenergetics and the formation of mitochondrial reactive oxygen species. Trends Pharmacol Sci 2006, 27:639-645.

42. Muller FL, Liu Y, Van Remmen H: Complex III releases superoxide to both sides of the inner mitochondrial membrane. J Biol Chem 2004, 279:49064-49073.

43. Kim JS, He L, Lemasters JJ: Mitochondrial permeability transition: a common pathway to necrosis and apoptosis. Biochem Biophys Res Commun 2003, 304:463-470.

44. Kim CH, Jeon HM, Lee SY, Jeong EK, Ju MK, Park BJ, Park HG, Lim SC, Han SI, Kang HS: Role of reactive oxygen species-dependent protein aggregation in metabolic stress-induced necrosis. Int J Oncol 2010, 37:97-102.

45. Zorov DB, Filburn CR, Klotz LO, Zweier JL, Sollott SJ: Reactive oxygen species (ROS)-induced ROS release: a new phenomenon accompanying induction of the mitochondrial permeability transition in cardiac myocytes. J Exp Med 2000, 192:1001-1014.

46. Zorov DB, Juhaszova M, Sollott SJ: Mitochondrial ROS-induced ROS release: an update and review. Biochim Biophys Acta 2006, 1757:509-517.

47. Alirol E, Martinou JC: Mitochondria and cancer: is there a morphological connection? Oncogene 2006, 25:4706-4716.

48. Brandon M, Baldi P, Wallace DC: Mitochondrial mutations in cancer. Oncogene 2006, 25:4647-4662.

49. Zong WX, Ditsworth D, Bauer DE, Wang ZQ, Thompson CB: Alkylating DNA damage stimulates a regulated form of necrotic cell death. Genes Dev 2004, 18:1272-1282.

doi:10.1186/1476-4598-10-113

Cite this article as: Lee et al:: Homeobox gene Dlx-2 is implicated in metabolic stress-induced necrosis. Molecular Cancer 2011 10:113. 